\title{
ARTICLE \\ Incorporating sea surface temperature into the stock- recruitment relationship: Applications to jack mackerel (Trachurus murphyi) off Chile
}

Incorporando la temperatura superficial del mar en la relación stock-reclutamiento: Una aplicación para el jurel (Trachurus murphyi) en Chile

\section{Fernando Espíndola ${ }^{1}$, Juan Carlos Quiroz ${ }^{2,1}$, Rodrigo Wiff ${ }^{3}$ and Eleuterio Yáñez}

\begin{abstract}
'División de Investigación Pesquera, Instituto de Fomento Pesquero, Casilla 8V, Valparaíso, Chile. fernando.espindola@ifop.cl ${ }^{2}$ Institute for Marine and Antarctic Studies, University of Tasmania (UTAS), 49 Private Bag, Hobart 7001, Australia

${ }^{3}$ Center of Applied Ecology and Sustainability (CAPES), Pontificia Universidad Católica de Chile, Av. Alameda 340, Santiago, Chile ${ }^{4}$ Escuela de Ciencias del Mar, Facultad de Ciencias del Mar y Geografía, Pontificia Universidad Católica de Valparaíso, Casilla 1020, Valparaíso, Chile
\end{abstract}

Resumen.- Se modeló la tasa de reclutamiento en relación a la biomasa desovante y la temperatura superficial del mar (TSM) para la población de jurel (Trachurus murphyi) afuera de las costas de Chile usando el modelo de Ricker. Los datos respecto al reclutamiento y la biomasa desovante fueron proporcionados por los modelos de evaluación de stock desde 1975 al 2001 , mientras que la serie temporal anual de TSM fue tomada de las estaciones meteorológicas localizadas a lo largo de la costa de Chile por el Centro Nacional de Datos Hidrográficos y Oceanográficos de Chile (CENDHOC). El modelo estándar de Ricker fue modificado de la siguiente manera: (1) incluyendo la serie temporal de TSM como un predictor lineal, (2) modelando la serie temporal de TSM con funciones de suavización y (3) modelando ambas, la biomasa desovante y la serie temporal de TSM con funciones de suavización. Los modelos resultantes fueron comparados con el modelo estándar de Ricker sin TSM. La selección del modelo se realizó según los criterios de información automática. La inclusión de la TSM mejora el ajuste de esos modelos, a pesar de la penalización de un término adicional y una posible fuente de variabilidad adicional. El mejor modelo resultante incorpora la serie temporal de TSM con funciones de suavización y la biomasa desovante mediante funciones paramétricas, con una bondad de ajuste del 90\%. La incorporación de una variable ambiental en la relación stock-reclutamiento puede ser un método promisorio para considerar los efectos de la pesca y el ambiente simultáneamente, y es particularmente relevante para el manejo pesquero a la luz del cambio climático.

Palabras clave: Modelos aditivos generalizados, relación stock-reclutamiento, TSM, no-paramétricos

\begin{abstract}
The recruitment rate was modeled in relation to spawning biomass and to sea surface temperature (SST) for the jack mackerel (Trachurus murphyi) population off the Chilean coast using the Ricker model. Data regarding recruitment and spawning biomass were obtained from indirect stock assessment models from 1975 to 2001, while annual time series of SST were collected from the meteorological stations placed along the Chilean coast by the National Center of Hydrographic and Oceanographic Data (CENDHOC). The standard Ricker model was thus modified as follows: (1) the SST temporal series was included as a linear predictor; (2) the SST temporal series was modeled through smoothing functions; and (3) spawning biomass and SST temporal series were both modeled using smoothing functions. The resulting models were compared with the standard Ricker model without SST. Model selection was carried out using automatic information criteria (AIC). Including SST improved the fit of the recruitment model, despite the penalty of an additional term and a possible additional source of variability. The best model resulting includes the SST temporal series with smoothing functions and the spawning biomass with parametric functions, with a goodness-of-fit of $90 \%$. Incorporating an environmental variable into stock-recruitment relationships may be a promising method for simultaneously considering effects from fishing and the environment, and is particularly relevant for managing fisheries in light of climate change.
\end{abstract}

Key words: Generalized additive models, stock-recruitment relationships, SST, non-parametric

\section{INTRODUCTION}

One of the most critical challenges in modeling harvested populations is in determining the relationship between reproductive population size and that of its offspring. Several theoretical models have attempted to describe the functional relationship between spawning biomass and the resulting recruitment in following years (Ricker 1954, Hilborn 1985, Hilborn \& Walters 1992, Quinn \& Deriso 1999). However, the goodness-of-fit of such models is often limited, mainly as 
a consequence of: (i) short temporal extent of recruitment series data, which preclude its use for predictive models and generally prevents contrast among data points; (ii) the inclusion, in many cases, of compensatory or depensatory effects, which do not explain the high variability in recruitments; and (iii) theoretical models that are generally only focused on including densitydependent effects affecting recruitment, ruling out densityindependent processes (Walch 1986).

During recent decades, the idea that environment may impact the stock-recruitment relationship, suggesting that population dynamics may be better understood by proposing alternative formulations to the classical stock-recruitment models, has grown in popularity (Tyler \& Crawford 1991, Ware 1996, Chen \& Ware 1999, Chen 2001, Chen \& Irvine 2001, Levi et al. 2003, Mikkelsen \& Pedersen 2004, Sinclair $\&$ Crawford 2005). Different parameterizations of the classical stock-recruitment models (e.g., Beverton-Holt, Ricker) have revealed the need for including compensatory and/or depensatory effects stemming from the environment. Stocker et al. (1985) established a relationship between the herring (Clupea harengus) recruitment rate and SST in the Strait of Georgia, which shows a dome-shape functional form, while Jacobson \& MacCall (1985) showed evidence of a non-linear form between reproductive success and average SST for the Pacific sardine (Sardinops sagax). Liermann \& Hilborn (1997) developed a hierarchical Bayesian model in order to describe the probable distribution of depensatory effects in 4 different fish taxa. Myers et al. (1995) analyzed 129 fish stocks, searching for evidence of density-dependent effects, and found only 3 stocks with lower recruitment than that predicted by classical models. In spite of these advances, investigation on the re-formulation or expansion of stockrecruitment models, in order to allow for the incorporation of density-independent processes, has been scarce. That said, the inclusion of environmental variables into the stockrecruitment relationship has been done in 2 ways. The first involves a parametric approach, where the mathematical formulation of the recruitment model is expanded by including parameters with environmental connotations, as suggested by Loucks \& Sutcliffe (1978). The other corresponds to the conceptual re-formulation of the stock-recruitment relationship, allowing for a better representation of the observations (Chen \& Ware 1999).

Along the Chilean coast, the jack mackerel has been considered one the most important target fish for fisheries with catches ranging from around 1.3 to 4.4 million tons during the period from 1970 to 2000 (Arcos et al. 2001), and the majority of which is caught by industrial purse-seiner fleets that operate in the central-southern area off Chile. The main spawning period of the jack mackerel throughout this wide distribution zone occurs in austral spring, from October to December (Arcos et al. 2001). During this period, the jack mackerel spawn over a wide area in oceanic waters off central Chile (Cubillos et al. 2008), known as the Subtropical Convergence Zone (SCZ). The SCZ, extends from the Chilean coast to between $150^{\circ} \mathrm{W}-160^{\circ} \mathrm{W}$, with a sea surface temperature (SST) ranging between 15 and $19^{\circ} \mathrm{C}$ (Núñez et al. 2010). During spawning, the relationship between egg density and SST was dome-shaped for all surveys taken from 1998-2001; egg densities were higher in waters where temperatures ranged between 14 and $19^{\circ} \mathrm{C}$, and declined at higher SST (Cubillos et al. 2008). The importance of SST as an environmental factor is widely recognized, as it is potentially capable of affecting inter-annual and multi-decadal fluctuations in fish abundance (Sissenwine 1984, Schwartzlose et al. 1999, Alheit \& Bakun 2010) at different spatio-temporal scales (Alheit \& Ñiquen 2004, Bertrand et al. 2004, Tourre et al. 2007). Based on the above information, we hypothesize that changes in sea surface temperature might provide adequate habitat conditions for the eggs and larvae of jack mackerel, and consequently recruitment success.

In sum, this works aims to assess the incorporation of sea surface temperature (SST) into the stock-recruitment relationship, using both parametric and non-parametric approaches. These approaches have long been incorporated for other fish stock. A prominent example, Quinn \& Deriso (1999), introduced the average annual SST time series into their analysis, and showed that the extended Ricker model generalized to include this SST effect was statistically significant, with the best outcomes based on the sum of squared residuals and the goodness-of-fit values. The results of this and other studies have shown that using the annual SST time series as a co-variable increases the precision and predictive capacity of stock-recruitment models. We apply such approaches to incorporate SST into the stock-recruitment relationship for jack mackerel off Chile between 1970 and 2001. Previous jack mackerel studies have shown a strong relationship between the population dynamics and SST in the analysis of fish schools (Castillo et al. 1996), catch rates (Yáñez et al. 1996) and the spatial distribution structure of eggs (Cubillos et al. 2008). However, the incorporation of SST into the stock-recruitment relationship has not yet been explored along the Chilean coast.

\section{MATERIALS AND METHODS}

Recruitment and spawning stock biomass data were obtained from the results of the jack mackerel (Trachurus murphyi) stock assessment models carried out in 2001 (Serra et al. 
2002) $)^{1}$. The stock assessment is based on a statistical catchat-age model considering the following information: age composition of the catch, age composition of acoustic survey, and total landing. The stock assessment model was calibrated by abundance indexes derived from the standardization of the catch per unit effort, acoustic biomass index surveys (Córdova et al. 2002) $)^{2}$, and egg production indices (Cubillos et al. 2002) ${ }^{3}$. We considered these data sets since they represent the cycle of low to high jack mackerel production recorded for the 1970 to 2001 period (Arcos et al. 2001). Is important to note that, controls on fishing were implemented in 1997, for which there has been a drastic reduction and restructuring of the industrial purse seiner fleet off Chile since then. Annual SST time series were collected from the meteorological stations placed along the Chilean coast by the Centro Nacional de Datos Hidrográficos y Oceanográficos de Chile (CENDHOC). The data sets had been previously assessed using correlations and smoothing techniques (Green \& Silverman 1994).

\section{Extended Ricker Models}

A method generally used in fisheries to relate mature populations $(S)$ with the recruitment abundance $(R)$ at any given time $t$, was suggested by Ricker (1975), who proposed an exponential functional relationship of the form:

$$
R_{t}=S_{t} e^{\left[a-b S_{t}\right]}
$$

where $a$ and $b$ are describe population productivity at low density and capacity limited by density-dependence, respectively. We assume log-normally distributed recruitment, then

$$
\log \frac{R_{t}}{S_{t}}=a-b S_{t}+\varepsilon_{t}
$$

where

$$
\log \frac{R_{t}}{S_{t}}
$$

is the response $\left(y_{t}\right)$ of the linear model that represents the recruitment rate per unit of spawning biomass, and $\varepsilon_{t}$ is the Gaussian error, such that $\varepsilon_{t} \sim N\left(0, \sigma^{2}\right)$ (hereafter, this model will be called the Ricker model, or RM). The main biological assumption of the Ricker model is that high values of $b$ cause an over compensation, reducing survival of pre-recruits at higher spawning stock size. This does not occur with other stock recruitments models. Chen \& Irvine (2001) extended the Ricker model (hereafter, extended Ricker model or ERM) to include environmental variables as follows:

$$
y_{t}=a-b S_{t}+\sum_{i} c_{i} Z_{i, t}+\varepsilon_{t}
$$

where $Z_{i t}$ with $i \in\{1, \ldots, k\}$ represents the environmental variables measured at time $t$.

Equation (3) can be expressed in terms of linear regression as follows:

$$
y_{t}=x_{t}^{T} \beta+z_{t}^{T} \gamma+\varepsilon_{t}
$$

where $y_{t}$ corresponds to the response vector, which in population theory represents an approximation to the population productivity, $\beta=(a,-b)^{T}$, and $x_{t}=\left(1, S_{t}^{*}\right)$ represents the vectors for biological and spawning biomass parameters while $\gamma=\left(c_{1}, \ldots, c_{k}\right)^{T}$ and $\mathrm{z}_{\mathrm{t}}=\left(Z_{1, t}, \ldots, Z_{k, t}\right)$ are the values for a group of $k$ parameters and predictors associated with environmental effects. It is assumed that predictions spread around an additive error of the form $\varepsilon_{t} \sim N\left(0, \sigma^{2} I\right)$, where $I$ is the identity matrix for the group of parameters.

Although the ERM parameter (eq. 4) can be estimated using multiple linear regression, a number of relevant works (Hilborn 1985, Jacobson \& MacCall 1985, Stocker et al. 1985, Fargo \& McKinnell 1989, Chen \& Irvine 2001) have shown that the relation between $y_{t}$ and $z_{t}$ may take different functional forms that clearly fail the assumption of log-linearity.

\section{Non-Parametric Ricker Model}

A proper and elegant form for relaxing the log-linearity assumption between $y_{t}$ and $z_{t}$ is the implementation of a nonparametric function, let us say $g(\cdot)$ for the co-variables $z_{t}$ included in the ERM such that $z_{t} \rightarrow g\left(z_{t}\right)$. Thus, the vector $\mathrm{z}_{\mathrm{t}}=\left(Z_{1, t}, \ldots, Z_{k, t}\right)$ may be represented in an additive form through $\left(z_{t}\right)=\sum_{i=1}^{k} g_{i}\left(Z_{i, t}\right)$ which defines a group of functions $g(\cdot)$ that may be solved non-parametrically and thus avoid the use of parameter vectors such as $\gamma=\left(c_{1}, \ldots, c_{k}\right)$. Following the formulation suggested by Chen \& Irvine (2001), the ERM can be re-written as:

\footnotetext{
${ }^{1}$ Serra R, C Canales, P Barria, J Cordova, A Aranis \& G Bohm. 2002. Informe final investigación captura total permisible jurel, 2002,88 pp. IFOP, Valparaíso.

${ }^{2}$ Córdova JM, MA Barbieri, M Espejo, S Núñez, J Ortiz, F Vejar, L Bustos, V Catasti, V Valenzuela, H Rebolledo \& P Torres. 2002. Evaluación hidroacústica de jurel en la ZEE, año 2002. Informe Final FIP 2002-02: 1-198. IFOP e INPESCA, Santiago de Chile.

${ }^{3}$ Cubillos L, MA Barbieri, C Oyarzún, S Gacitúa \& G Aedo. 2002. Condición biológica de jurel en alta mar, año 2001. Informe Final FIP 2001-12: 1-168. INPESCA, IFOP y UdeC.
} 


$$
y_{t}=x_{t}^{T} \beta+g\left(z_{t}\right)+\varepsilon_{t}
$$

where $g\left(z_{t}\right)$ is the non-parametric term, for which in the theoretical approach of Generalized Additive Models (GAM) is commonly used as smoothing technique. The conceptualization of equation (eq. 5) includes two components, where the first involves a parametric term $x_{t}^{T} \beta$ equivalent to the right side of the RM, while the second corresponds to a non-parametric term $g(\cdot)$ that represents the environmental variables. Thus, this formulation represents a semi-parametric version of the Ricker model (hereafter, SPRM).

Hilborn \& Walters (1992) showed that $E\left(e^{\varepsilon t}\right)=\mu \neq 0$ when $\varepsilon_{\tau} \sim N\left(0, \sigma^{2}\right)$. Therefore, the stock-recruitment function of the RM or ERM should not be described by the group of parameters $\beta$ in a real scale (for details see Hilborn 1985). Thus, after a mathematical generalization of SPRM, we obtain,

$$
y_{t}=f\left(x_{t}\right)+g\left(z_{t}\right)+\varepsilon_{t}
$$

degrees of freedom of the smoother. Statistical analyses and figures were implemented using $R$ programming language and statistical computation (R Development Core Team 2012) ${ }^{1}$.

\section{Results}

Exploration of the $R$ and SST time series reveals an important degree of correlation, which is mainly explained by the trend changes occurring between 1984 and 2000. This period was characterized by a reduction of close to $50 \%$ in the recruitment and observed SST (Fig. 1). On the other hand, after assessing the annual productivity of the jack mackerel population, $y_{t}$ (eq. 3 ), it becomes obvious that a linear assumption between $y_{t}$ and

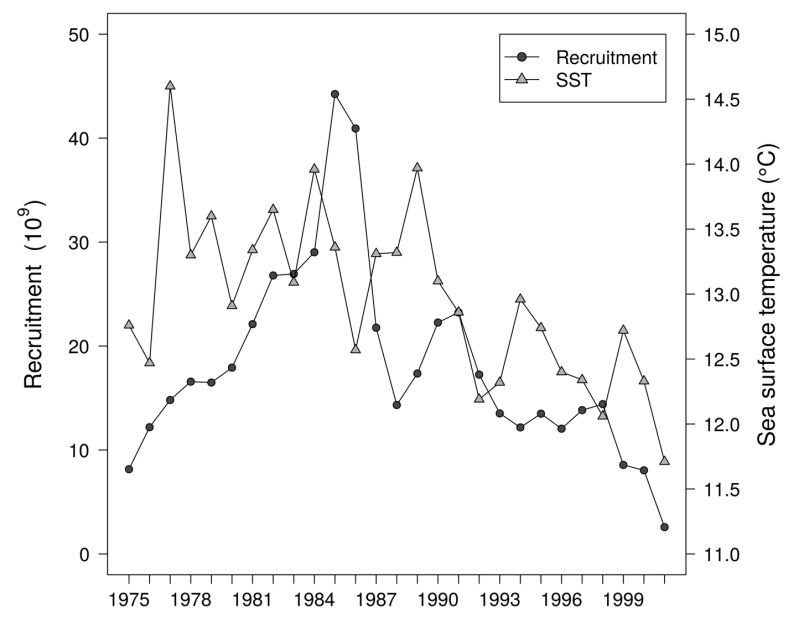

Figure 1. Recruitment time series off jack mackerel and sea surface temperature between 1975-2001 / Series temporales del reclutamiento de jurel y la temperatura superficial del mar entre 1975-2001
SST is inadequate (Fig. 2a). In this context, a significant improvement $(\mathrm{F}=4.73, P<0.005)$ was found after implementing a non-linear relationship (Fig. 2b). Furthermore, Figure 2 suggests that SST is a suitable predictor of the inter-annual variations of $y_{t}$, with an increase of 1.19 units of stock productivity per each increase in unit of SST. Additionally, the effects of SST on $y_{t}$ are clearly positive for results exceeding $13^{\circ} \mathrm{C}$, a range of values for which the maximum increases in stock productivity are reached (Fig. 1). However, effects on $y_{t}$ for SST below $13^{\circ} \mathrm{C}$ are lower, and tend to predict low recruitments.

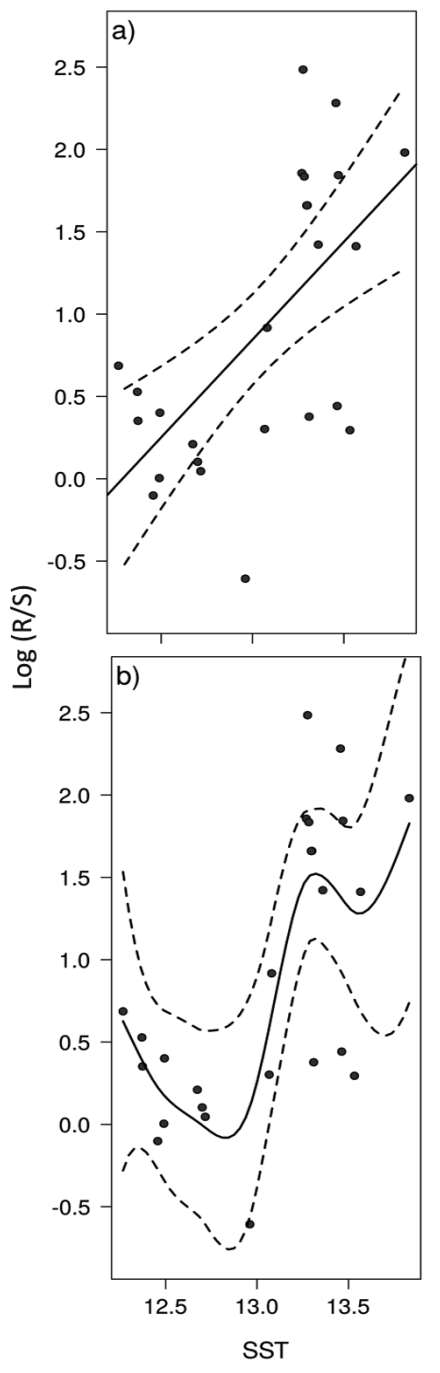

Figure 2. Relationship between SST and the recruitment rate for the jack mackerel population. (a) Usinga parametric lineal function and (b) using a non-parametric smoothing function. The dotted lines correspond to the $95 \%$ confidence intervals. Black dots correspond to the observed values / Relación entre la TSM y la tasa de reclutamiento para la población de jurel. (a) Usando una función lineal paramétrica y (b) usando una función de suavización no-paramétrica. Las líneas punteadas corresponden a los intervalos de confianza al $95 \%$. Los círculos negros corresponden a los valores observados 
The implementation of ERM (eq. 3) with the incorporation of SST as a co-variable is statistically better than RM alone $(\mathrm{F}=26.35, P<0.005$, Table 1$)$, meaning that SST is a suitable predictor for the stock-recruitment model. In fact, when SST is parametrically incorporated into the ERM, the sum of squared residuals (SSR) is reduced to some $30 \%$ of the SSR of the RM (Table 1). Notwithstanding, exploratory analysis showed that a linear assumption with ERM for SST was unsatisfactory when compared to a non-linear model (Fig. 2). This became evident after exploring SPRM results (eq. 5), which significantly exceed the goodness-of-fit for linear models of RM and ERM. Indeed, the determination coefficient for the SPRM is $r^{2}=0.90$, a value which is notably superior to the $r^{2}=0.5$ of the RM, and slightly improves on the ERM value $r^{2}=0.83$ (Table 1). In addition, when non-parametric functions are introduced for both predictors, the SPRM fit (eq. 6) becomes statistically significant ( $\mathrm{F}=5.01, P<0.005)$, with a determination coefficient close to 0.95. Although this increase in the goodness-of-fit of the SPRM is associated with a reduction to eight degrees of freedom (Table
1), making this model one of the best candidates to reproduce the inter-annual variation of $y_{t}$, it also implies significant difficulty regarding the biological interpretation of the predictor $x_{t}$ and the vector of parameter $\beta=(a,-b)^{T}$.

Table 1. Summary of fitted models/ Resumen de los modelos ajustados

\begin{tabular}{|c|c|c|c|c|c|c|}
\hline \multirow{2}{*}{ Predictor } & \multirow{2}{*}{ Vector } & \multirow{2}{*}{ Parameters } & \multicolumn{4}{|c|}{ Model } \\
\hline & & & RM & ERM & SPRM & NPRM \\
\hline$x_{t}$ & $\beta$ & $a$ & 1.99 & -6.09 & -5.48 & -5.31 \\
\hline$x_{t}$ & $\beta$ & $b$ & 0.13 & 0.12 & 0.13 & 0.13 \\
\hline \multirow[t]{4}{*}{$z_{t}$} & $\gamma$ & $c$ & $*$ & 0.62 & 0.58 & 0.57 \\
\hline & & SSR & 8.88 & 2.68 & 1.71 & 0.91 \\
\hline & & $r^{2}$ & 0.5 & 0.83 & 0.9 & 0.95 \\
\hline & & $g l$ & 23 & 21 & 18 & 15 \\
\hline
\end{tabular}

* : unimplemented

Note: RM represent the traditional Ricker model (eq. 1), ERM the extended Ricker model (eq. 4), SPRM is the semi-parametric Ricker model (eq. 5) and NPRM is the non-parametric Ricker model (eq. 6). $S S R$ is the sum of squared residuals, $r^{2}$ is the goodness-of-fit and $g l$ is degree of freedom

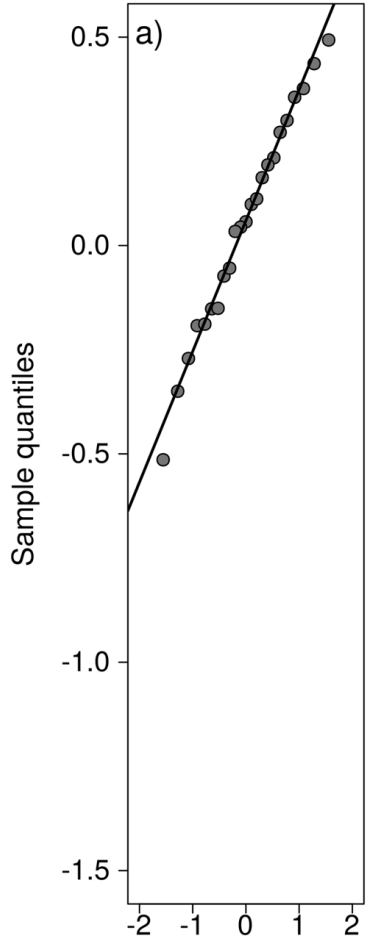

Theorical quantiles
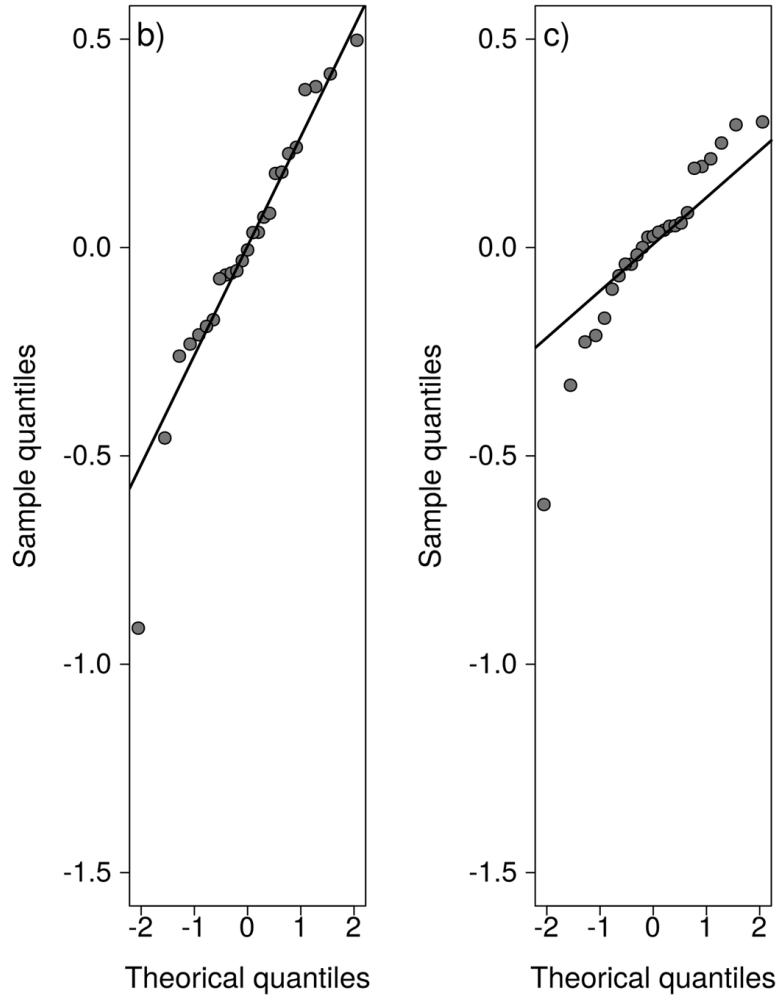

Figure 3. Quantile-quantile plot for the residuals of the models (a) extended Ricker model (ERM), (b) semi-parametric Ricker model (SPRM) and (c) non-parametric Ricker model (NPRM) / Gráfica para los quantiles de los residuales de los modelos (a) extendido de Ricker (MER), (b) modelo semi-paramétrico de Ricker (MSPR) y (c) modelo no-paramétrico de Ricker (MNPR) 
Regarding the biological interpretation, all models showed very similar and statistically significant $(\mathrm{F}=37.48, P<0.005)$ density-dependent parameters ( $b S_{t}$ eq. 2 ). This situation was expected as this parameter is directly related to the population productivity. In contrast, the results show different values for the density-independent parameter ( $a$, eq. 2 ), a situation consistent with the intercept changes assumed for each structure of the models described in the preceding section. In general, the residual distributions for the models incorporating SST as environmental co-variable are close to a normal distribution (Fig. 3 ). This result was statistically confirmed by applying the Kolmogorov-Smirnov tests to the ERM $(\mathrm{F}=0.28, P<0.05)$, $\operatorname{SPRM}(\mathrm{F}=0.32, P<0.05)$ and NPRM $(\mathrm{F}=0.38, P<0.05)$, thus ensuring that SST incorporation in the models satisfies the normality assumptions.

\section{Discussion}

Recruitment variations have been consistently attributed to environmental changes or variations in the reproductive stock at different temporal and spatial scales (Sissenwine 1984, Schwartzlose et al. 1999, Alheit \& Ñiquen 2004, Bertrand et al. 2004, Tourre et al. 2007, Alheit \& Bakun 2010). Disentangling such effects is difficult, as recruitment generally presents high variability combined with short time series for available data (Planque \& Frédou 1999). In this work, the effect of each factor was isolated with a combination of functions that included or excluded a parametric relationship for both environmental and productive factors. We believe that the parametric selection of a function does not depend only on the statistical goodness-of-fit; rather, the selection of a parametric function involves the acceptance of a causal mechanism between the modeled variables, while the non-parametric functions provide only a phenomenological description of the relationship between variables (modeling the data without a causal explanation). The results indicate that the inclusion of SST is significant in a parametric model (ERM); and when it is included in non-parametric form (SPRM and NPRM), the explanation of the total variance of the model increases. A similar situation is observed with the term of productivity, which increases the explanation of variance when it is modeled in a non-parametric form. However, when assessing the change in the variance explained after including non-parametric functions, the SST is more relevantly affected than is the population productivity, due to the non-linearity observed in the SST. In this context, the most parsimonious model for the stock-recruitment relationship of jack mackerel including SST is suggested, i.e., the semiparametric Ricker Model (SPRM). In this model, the productivity component is assumed to be parametric and resulting from a causal mechanism, while SST is modeled by non-parametric functions and does not account for any causeeffect mechanism for how SST might affect recruitments. The assumption of a completely non-parametric model precludes the interpretation of the relationship between productivity and recruitment. On the other hand, it is known that densitydependent mechanisms affecting recruitment are properly established and recognized in the theory of population renewal (Quinn \& Deriso 1999), while examples in which the environmental variable demonstrates a causal mechanism on recruitment are scarce (Wiff \& Quiñones 2004).

Environmental temperature has been pointed out as one of the main abiotic factors affecting practically all biological processes (Charnov \& Gillooly 2004). There are several studies where recruitment is associated with environmental temperature; however, many of them have only a descriptive character. Causal mechanisms may be modeled under the context of predictive functions, such as those presented in this work. The form in which SST affects recruitment has been suggested as an indirect mechanism, where SST acts as a proxy variable associated with marine productivity at lower trophic levels (Rothschild 1994). Our results suggest that recruitment increases with SST and is graphically represented by a sigmoid-type function where the asymptotic recruitment is found at levels of $13.3^{\circ} \mathrm{C}$ of SST. Núñez et al. (2010) and Cubillos et al. (2008) have suggested that early stages of jack mackerel reproduction are associated with high SST isotherms, generally between $15^{\circ}$ and $16^{\circ} \mathrm{C}$. On the other hand, the same sigmoid relationship between SST and egg abundance for jack mackerel has been reported (Cubillos et al. 2008). Although the mechanism relating the early stages of jack mackerel reproduction to SST has not been yet established, it has been indicated that the spawning process may be confined to the Subtropical Convergence Zone (Núñez et al. 2010), which is a wide area in oceanic waters characterized by the presence of high gradients of temperature and salinity produced by the convergence and divergence of the sea surface currents that favor primary and secondary production (Olson \& Backus 1985). These strong thermal gradients can cause changes in the timing of peak spawning and may dislocate spawning away from traditional spawning grounds (Laevastu 1993, Maravelias 1997).

In this study, recruiters refer to two-year old fish, which positively recruit in relation to the mean SST of the studied area. Although both processes are associated with warm waters, the change in the scale shown by the recruitment and SST relationship compared to the relation between early reproductive stages and SST may be the result of the nature of the SST data. Here, we used the annual average of daily data obtained from Talcahuano bay, while the studies for early stages use the in situ mean SST. However, along the coast of South America, 
SST variability decreases poleward from subtropical latitudes and is mainly related to the ENSO cycle (Enfield \& Allen 1980, Montecinos et al. 2003). In addition, high spatial correlations are found in the adjacent area along the coast of South America, located from $15^{\circ} \mathrm{S}$ to $35^{\circ} \mathrm{S}$ in relation to coastal time series (Montecinos et al.2003). In this context, and for this particular study, the coastal SST time series could be considered as a proxy variable for large oceanic jack mackerel spawning.

The causes associating early recruitment stages with SST are still unknown and further analysis is required, probably using complementary information allowing for approaches to the causal mechanism. The identification of causal mechanisms showing how environmental variables influence recruitment would be significant for the development of stock-recruitment models with predictive capacity. The latter may be particularly important for harvested populations, in as far as evidence emphasizes the need for direct efforts to incorporate environmental variability into standard biological-fisheries models (Wiff \& Quiñones 2004). Changes in population structures have been reported particularly for the reduction of those age classes associated with recruitment fluctuations and fishery exploitation (Marteinsdottir \& Thorarinson 1998) and for the variation of intensity and spawning periods in relation to the individual body size (Kjesbu et al. 1996). In this sense, Ottersen et al. (1994) have added that populations with a reduced composition of age spawn over smaller geographical areas and for shorter periods, thus making the population more sensitive to changes in the environmental conditions. Under such a scenario, it is plausible that strongly exploited populations, such as the jack mackerel off Chile, will show amplified responses to small and medium-scale spatial-temporal changes. Many authors have suggested that density-dependent processes controlling population renewal are weak (Goodyear \& Christensen 1984) and, therefore, the recruitment variations over time respond to processes which are highly independent from the stock size.

Finally, since the population of jack mackerel is recovering from a condition of overfishing in an environmentally unfavorable (warm) climate, the fishing mortality for the stock assessments model should be adjusted to account for the predicted recruitment under current environmental climate conditions and spawning biomass. In addition, considerable improvements in the stock-recruitment relationship model modified by the inclusion of the environment variable could be made by incorporating first-order autocorrelation model for residuals; lagged effects of environmental variables; and the combined effects of multiple environmental variables, like salinity, surface mixer layer, chlorophyll, sea level anomalies, current surface fields, and many others. In concluding, we have shown the efficacy of incorporating environmental variables in order to improve recruitment prediction of jack mackerel off Chile. The usefulness of the models here implemented may have a direct influence on resource management, as they contribute towards obtaining less-biased abundance estimations. These estimates are probably more precise and involve better predictive capacity, as they simultaneously take into account the effects of fishing and those of the environment, which is particularly important as the effects of climate change continue to be a concern in management and policy.

\section{ACKNOWLEDGMENTS}

We are grateful to two anonymous reviewers for their valuable comments and suggestions. We would also like to acknowledge the Centro Nacional de Datos Hidrográficos y Oceanográficos de Chile (CENDHOC), of the Servicio Hidrográfico y Oceanográfico de la Armada de Chile (SHOA) for supplying the sea surface temperature data requested through their website. R. Wiff was funded by CONICYT/FONDECYT post doctoral project number 3130425 and by CAPES project Conicyt FB 0002 (2014). J.C. Quiroz was awarded with the CONICYT BECAS-CHILE scholarship from the Chilean Government and the top-up Flagship Postgraduate Scholarship from the University of Tasmania.

\section{LITERATURE CITED}

Alheit J \& A Bakun. 2010. Population synchronies within and between ocean basins: Apparent teleconnections and implications as to physical-biological linkage mechanisms. Journal of Marine Systems 79: 267-285.

Alheit J \& M Ñiquen. 2004. Regimen shifts in the Humbolt Current ecosystem. Progress in Oceanography 60: 201-222.

Arcos D, L Cubillos \& S Núñez. 2001. The jack mackerel fishery and El Niño 1997-98 effects off Chile. Progress in Oceanography 49: 597-617.

Bertrand A, M Segura, M Gutiérrez \& L Vásquez. 2004. From small-scale habitat loopholes to decadal cycles: a habitat-based hypothesis explaining fluctuation in pelagic fish populations off Peru. Fish and Fisheries 5: 296-316.

Castillo J, MA Barbieri \& A González. 1996. Relationships between sea surface temperature, salinity and pelagic fish distribution off northern Chile. ICES Journal of Marine Science 53: 139-146.

Charnov EL \& JF Gillooly. 2004. Size and temperature in the evolution of fish life histories. Integrative and Comparative Biology 44: 494-497.

Chen DG. 2001. Detecting environmental regimes in fish stockrecruitment relationships by fuzzy logic. Canadian Journal of Fisheries and Aquatic Sciences 58(11): 2139-2148. 
Chen DG \& JR Irvine. 2001. A semiparametric model to examine stock-recruitment relationships incorporating environmental data. Canadian Journal of Fisheries and Aquatic Sciences 58(6): 1178-1186.

Chen DG \& DM Ware. 1999. A neural network model for forecasting fish stock recruitment. Canadian Journal of Fisheries and Aquatic Sciences 56(12): 2385-2396.

Cubillos L, J Paramo, P Ruiz, S Núñez \& A Sepúlveda. 2008. The spatial structure of the oceanic spawning of jack mackerel (Trachurus murphyi) off central Chile (19982001). Fisheries Research 90(1-3): 261-270.

Enfield DB \& JS Allen. 1980. On the structure and dynamics of monthly mean sea level anomalies along the Pacific coast of North and South America. Journal of Physical Oceanography 10:557-578.

Fargo J \& S McKinnell. 1989. Effects of temperature and stock size on year class production for rock sole (Lepidopsetta bilineata) in northern hecate strait, british columbia. In: Beamish RJ \& GA MaFarlane (eds). Effects of ocean variability on recruitment and an evaluation of parameters used in stock assessment model. Canadian Special Publication of Fisheries and Aquatic Sciences 108: 327-333.

Goodyear CP \& SW Christensen. 1984. On the ability to detect the influence of spawning stock on recruitment. North American Journal of Fisheries Management 4: 186-193.

Green PJ \& BW Silverman. 1994. Nonparametric regression and generalized linear models: A roughness penalty approach, 184 pp. Chapman and Hall/CRC Monographs on Statistics \& Applied Probability, London.

Hastie TJ \& RJ Tibshirani. 1990. Generalized additive models, 352 pp. Chapman and Hall/CRC Monographs on Statistics \& Applied Probability, London.

Hilborn R. 1985. Simplified calculation of optimun spawning stock size from Ricker's stock recruitment curve. Canadian Journal of Fisheries and Aquatic Sciences 42: 1833-1834.

Hilborn R \& CJ Walters. 1992. Quantitative fisheries stock assessment: Choice, dynamics and uncertainty, $592 \mathrm{pp}$. Chapman and Hall, New York.

Jacobson LD \& AD MacCall. 1995. Stock-recruitment models for pacific sardine (Sardinops sagax). Canadian Journal of Fisheries and Aquatic Sciences 52: 566-577.

Kjesbu O, P Solemdal, P Bratland \& M Fonn. 1996. Variation in annual egg production in individual captive Atlantic cod (Gadus morhua). Canadian Journal of Fisheries and Aquatic Sciences 53: 610-620.

Laevastu T. 1993. Marine climate, weather and fisheries: The effects of weather and climatic changes on fisheries and ocean resources, 205 pp. Fishing News Books, Oxford, London.
Levi D, MGAndreoli, A Bonanno, F Fiorentino, G Garofalo, S Mazzola, G Norrito, B Patti, G Pernice, S Ragonese, GB Giusto \& P Rizzo. 2003. Embedding sea surface temperature anomalies into the stock recruitment relationship of red mullet (Mullus barbatus L. 1758) in the Strait of Sicily. In: Ulltang $\varnothing \&$ G Blom (eds). Fish stock assessments and predictions: Integrating relevant knowledge. Scientia Marina 67 (Suppl. 1): 259-268.

Liermann M \& R Hilborn. 1997. Depensation in fish stock: A hierarchic bayesian meta-analysis. Canadian Journal of Fisheries and Aquatic Sciences 54(9): 1976-1984.

Loucks RH \& WH Sutcliffe. 1978. A simple fish-population model including environmental influence, for two western Atlantic shelf stocks. Journal of the Fisheries Research Board of Canada 35: 279-285.

Maravelias CD. 1997. Trends in abundance and geographic distribution of North Sea herring in relation to environmental factors. Marine Ecology Progress Series 159: 151-164.

Marteinsdottir G \& K Thorarinson. 1998. Improving the stock-recruitment relationships in Iceland cod (Gadus morhua). Canadian Journal of Fisheries and Aquatic Sciences 55: 1372-1377.

Mikkelsen N \& T Pedersen. 2004. How can the stock recruitment relationship of the Barents Sea capelin (Mallotus villosus) be improved by incorporating biotic and abiotic factors? Polar Research 32(1): 19-26.

Montecinos A, S Purca \& O Pizarro. 2003. Interannual-tointerdecadal sea surface temperature variability along the western coast of South America. Geophysics Research Letters 30, 1570. <doi:10.1029/2003GL017345>

Myers RA, NJ Barrowman, JA Hutchings \& AA Rosenberg. 1995. Population dynamics of exploited fish stocks at low population levels. Science 269(5227): 11061108.

Núñez S, S Vásquez, P Ruiz \& A Sepúlveda. 2010. Distribution of early developmental stages of jack mackerel in the Southeastern Pacific ocean. Technical Report, Chilean Jack Mackerel Workshop. 11 pages. <https://www.sprfmo.int/ assets/Meetings/Meetings-before-2013/Scientific-WorkingGroup/Jack-Mackerel-Workshop-2008/02.CHJMWSDistribution-of-early-developmental-stages-of-jackmackerel-in-the.pdf>

Olson DB \& RH Backus. 1985. The concentrating of organisms at fronts: a cold-water fish and a warm-core Gulf stream ring. Journal of Marine Research 43: 113-137.

Ottersen G, H Loeng \& A Raknes. 1994. Influence of temperature variability on recruitment of cod in the Barents Sea. ICES Journal of Marine Science 55: 67-85.

Planque B \& T Frédou. 1999. Temperature and the recruitment of Atlantic cod (Gadus morhua). Canadian Journal of Fisheries and Aquatic Sciences 56: 2069-2077. 
Quinn TJ \& RB Deriso. 1999. Quantitative fish dynamics, 560 pp. Oxford University Press, New York.

Ricker WE. 1954. Stock and recruitment. Journal of the Fisheries Research Board of Canada 11: 559-623.

Ricker WE. 1975. Computation and interpretation of biological statistics of fish population. Bulletin of the Fisheries Research Board of Canada 191: 382.

Rothschild BJ. 1994. Decadal transients in biological productivity, with special reference to the cod population of the North Atlantic. ICES Marine Science Symposium 198: 333-345.

Schwartzlose R, J Alheit, A Bakun, T Baumgartner, R Cloete, R Crawford, W Fletcher, Y Green-Ruiz, E Hagen, T Kawasaki, D Lluch-Belda, SE Lluch-Cota, AD MacCall, Y Matsuura, MO Nevárez-Martínez, RH Parrish, C Roy, R Serra, KV Shust, MN Ward \& JZ Zuzunaga. 1999. Worldwide large-scale fluctuations of sardine and anchovy populations. South Africa Journal of Marine Science 21:289-347.

Sinclair AF \& WR Crawford. 2005. Incorporating an environmental stock-recruitment relationship in the assessment of Pacific cod (Gadus macrocephalus). Fisheries Oceanography 14(2): 138-150.

Sissewine MP. 1984. Why do fish populations vary? In: May RM (ed). Exploration of marine communities, pp. 59-94, Springer-Verlag, Berlin.
Stocker MV, V Haist \& D Fournier. 1985. Environmental variation and recruitment of pacific herring (Clupea harengus pallasi) in the strait of georgia. Canadian Journal of Fisheries and Aquatic Sciences 42(1): 174-180.

Tourre YM, SE Lluch-Cota \& WB White. 2007. Global multidecadal ocean climate and small-pelagic fish population. Environmental Research Letters 3(2): 034005 \& doi:10.1088/ 1748-9326/2/3/034005>

Tyler AV \& WR Crawford. 1991. Modeling of recruitment patterns in Pacific cod (Gadus macrocephalus) in Hecate Strait, British Columbia. Canadian Journal of Fisheries and Aquatic Sciences 48: 2240-2249.

Walch DW. 1986. Identifying the stock-recruitment relationship for age-structure populations using time-invariant matched linear filters. Canadian Journal of Fisheries and Aquatic Sciences 43: 108-123.

Ware DM. 1996. Herring carrying capacity and sustainable harvest rates in different climate regimes. Pacific Stock Assessment Revision Commission 96: 3-19.

Wiff R \& RA Quiñones. 2004. Parametrización ambiental en modelos biológico-pesqueros: Una revisión. Gayana 68(1): 111-127.

Yáñez E, V Catasti, MA Barbieri \& G Bohm. 1996. Relationships between the small pelagic resources distribution and the sea surface temperatures recorded by NOAA satellites from Chile central zone. Investigaciones Marinas 24: $107-122$. 